\title{
The application of the electroencephalograph for the measurements of changes of electric potential differences in plants
}

\section{A. PASZEWSKI}

I used Kaiser's Electroencephalograph (Copenhagen) for measuring change of differences of electric potentials in higher plants.

I suppose that the application of the electroencephalograph for research on higher plants could be interesting, as in the literature available to me I did not find measurements in the range of microvolts. Also the frequency can be more precisely tested. The amplification of the currents was $10^{7}$. The set has eight pairs of canals. Till this time I used only one pair of electrodes, but in future I intend to utilize all possibilities.

I used two platinum electrodes. At first I plugged them in the stem, later I hung them up on the plant. The set is joined to a writing-apparatus, which takes down automatically on a paper band the changes of potential differences and the frequencies of changes. The measurements were taken in a Faraday's cage. In this communication I state the result of the measurements of changes of potential differences and frequencies, which rose under the influence of several stimuli. For my experiments I used following plants: Pelargonium zonale, Mimosa pudica, Avena sativa.

I performed my investigations at a temperature of $18^{\circ} \mathrm{C}$, and an airmoisture of $70 \%$.

Plant Physiology Laboratory

Maria Curie-Sklodowska University

Lublin

\section{LITERATURA}

Diannenleidis Th., Umrath K., 1953, Über das elektrische Potential und über den Erregungs. vorgang bei dem Myxomyceten Physarum polycephalum. Protoplasma. Band XLII, Heft 3 . $312-323$.

Umrath Karl., 1956, Elektrophysiologische Phänomene. Handbuch der Pflanzenphysiologie. Band II. p. 747. Berlin.

Umrath Karl. p., 1959, Die Wirkung elektrischer Reize. Handbuch der Pflanzenphysiologie. Band XVII/1 p. 135 . Berlin. 


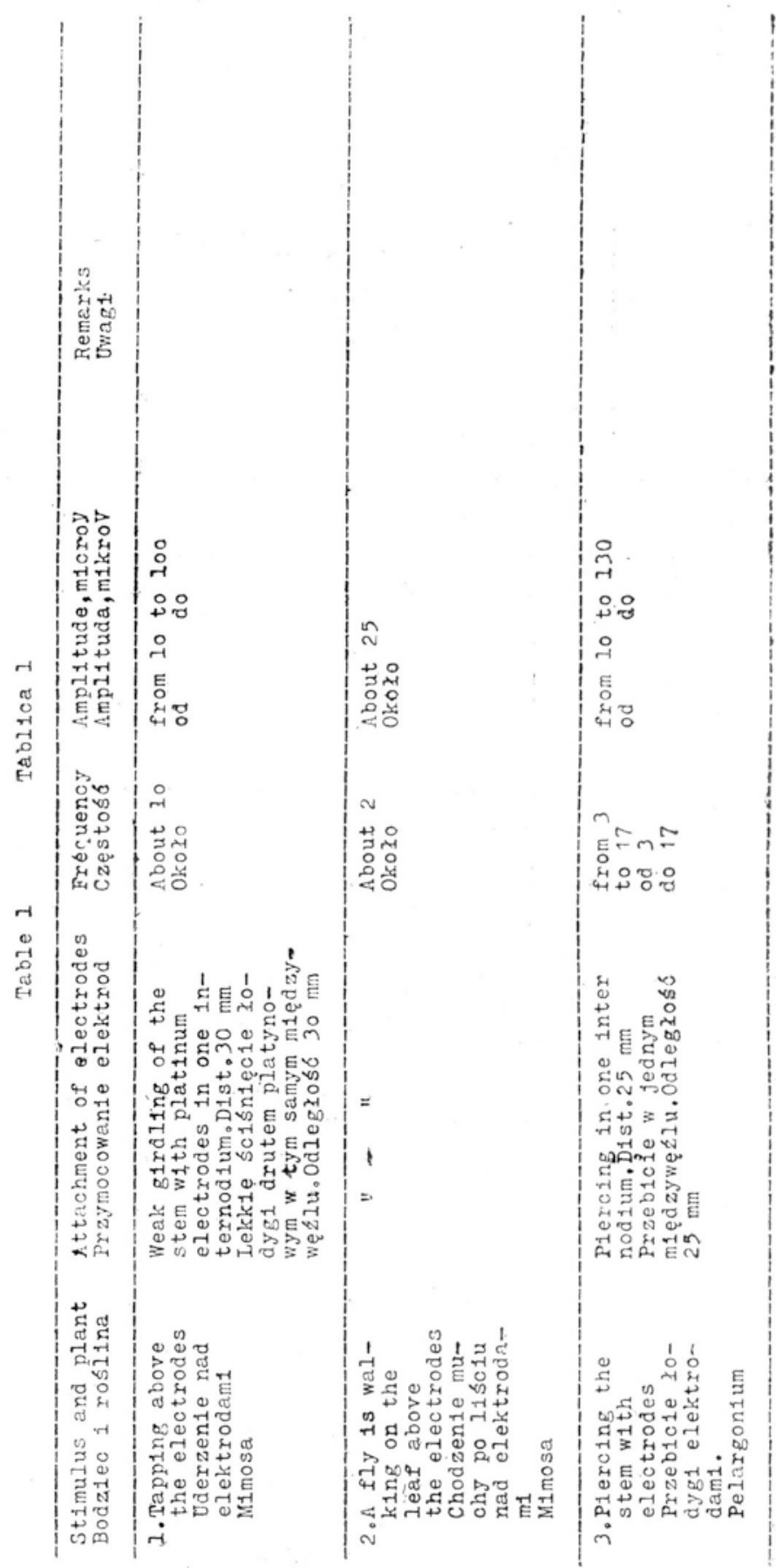




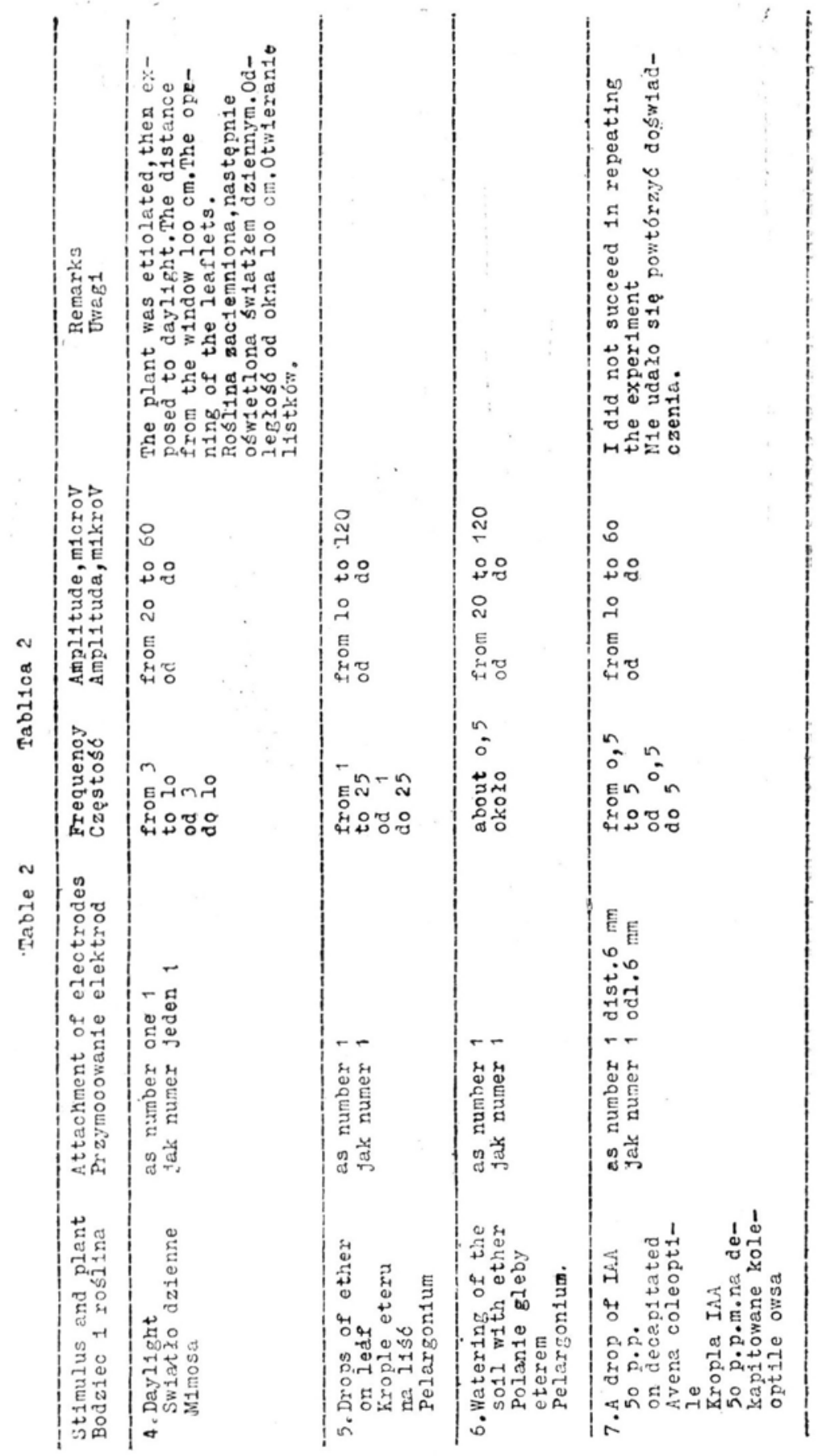




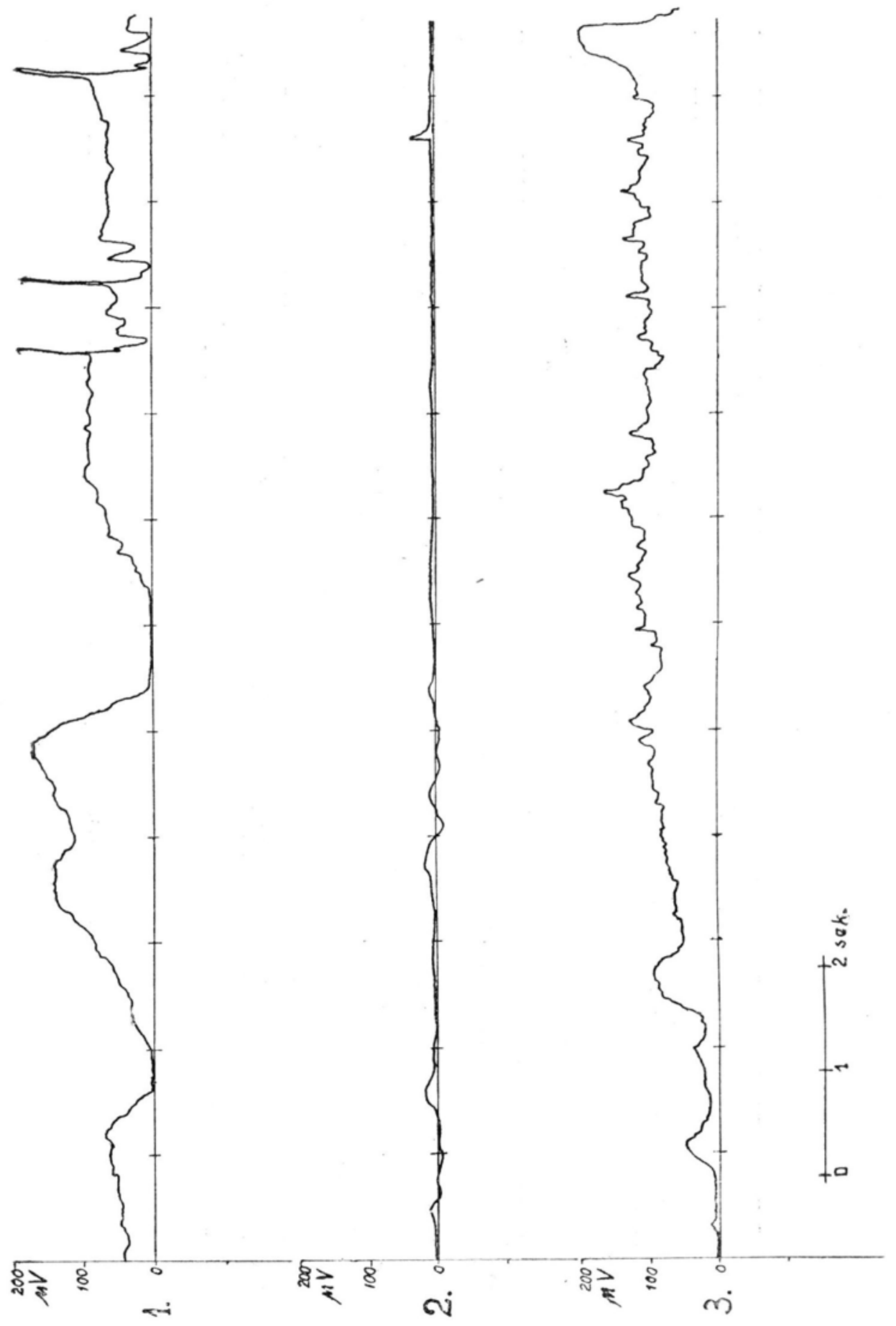




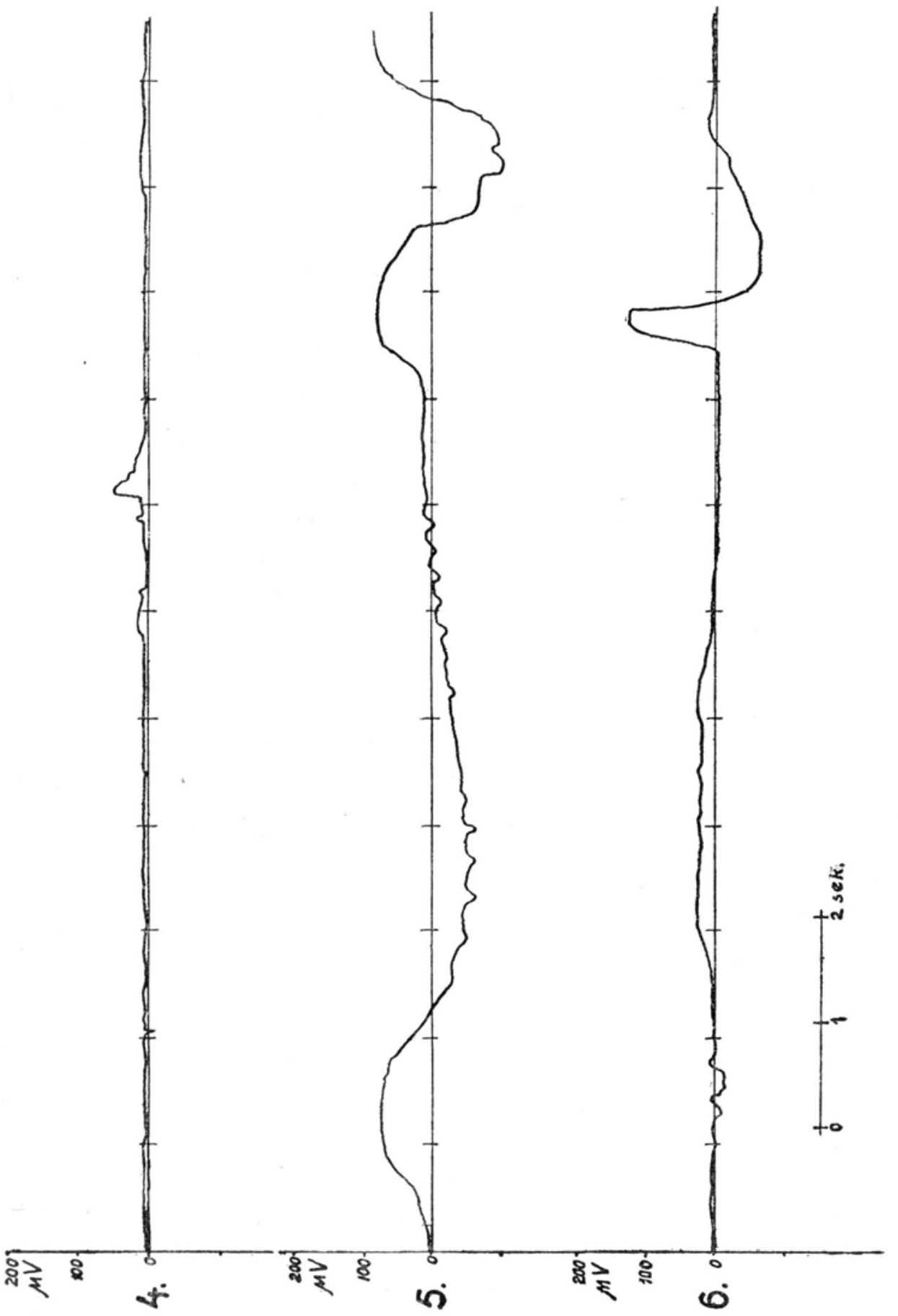




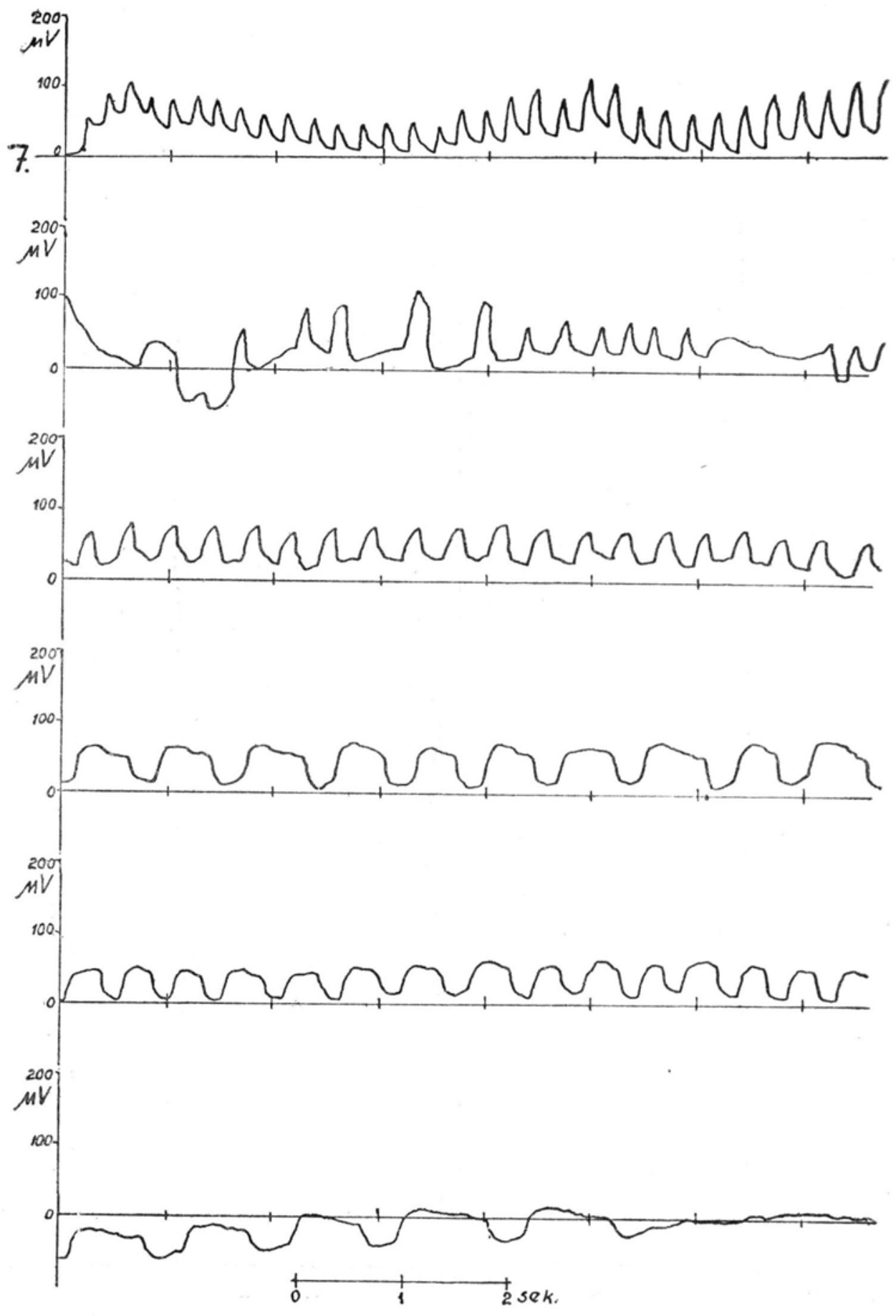

